\title{
Gastritis Cystica Profunda: A Rare Gastric Tumor Masquerading as a Malignancy
}

\author{
Joseph L. Laratta ${ }^{1}$, Tatiana N. Buhtoiarova ${ }^{2}$, Lauren S. Sparber ${ }^{3}$, Ronald S. Chamberlain ${ }^{1,3,4}$ \\ ${ }^{1}$ Department of Surgery, University of Medicine \& Dentistry of New Jersey, Newark, NJ, USA \\ ${ }^{2}$ Department of Pathology, Saint Barnabas Medical Center, Livingston, NJ, USA \\ ${ }^{3}$ Department of Surgery, Saint Barnabas Medical Center, Livingston, NJ, USA \\ ${ }^{4}$ St. George's University School of Medicine, Grenada, West Indies \\ Email: rchamberlain@barnabashealth.org
}

Received November 15, 2011; revised December 17, 2011; accepted January 10, 2012

\begin{abstract}
Introduction: Gastritis cystica profunda (GCP) is a rare tumor which occurs more commonly in patients with prior gastric surgery. The nonspecific symptoms and radiographic appearance of this tumor mimic that of other hyperproliferative conditions making diagnosis difficult without definitive surgical resection. This report provides a comprehensive review of GCP and all GCP cases reported to date. Methods: A comprehensive literature search (1972-2011) was conducted with all reported GCP cases analyzed. Keywords searched included gastritis cystica profunda, submucosal cysts of the stomach, and heterotopic submucosal gastric glands. Results: Thirty-seven GCP cases have been reported since 1972, which includes 29 (78\%) men and 8 (21\%) women (M:F ratio, 3.6:1). The overall mean age was 60.5 years (range, 39 - 81 years) with 55.6 years (range, 39 - 79) and 62.2 years (range, 39 - 81 years) in women and men, respectively. $65 \%(\mathrm{~N}=24)$ had prior gastric surgery. $62 \%(\mathrm{~N}=23)$ of GCP tumors were located in the body; $24 \%(\mathrm{~N}=9)$ in the fundus; $8 \%(\mathrm{~N}=3)$ in the antrum; or $6 \%(\mathrm{~N}=2)$ in the cardia of the stomach. GCP was an incidental finding in $19 \%$ of patients. Complete excision was performed most often (73\%) followed by endomucosal resection (18\%), and polypectomy (4.5\%). One patient underwent surveillance (4.5\%). Conclusions: GCP is a rare gastric tumor, which is difficult to diagnose preoperatively and masquerades as a malignancy. GCP is more common in men and typically presents with nonspecific symptoms. Although a benign lesion, GCP may represent an intermediate histology in the malignant progression to gastric neoplasia. To date, there have been no reports of local recurrence or distant metastasis following definitive surgical excision, which remains the standard of care.
\end{abstract}

Keywords: Gastritis Cystica Polyposa; GCP; Submucosal Cysts of the Stomach; Heterotopic Submucosal Gastric Glands

\section{Introduction}

Gastritis cystica profunda (GCP) has been infrequently described in the English literature. The histological findings of cystic glandular inclusions with a connective tissue laden submucosa were first described by Littler and Gleibermann in 1972 [1]. However, it was not until 1981 that Franzin and Novelli coined the term "gastritis cystica profunda," and described fifteen cases of GCP that were initially confused with other gastric pathologies, such as mature erosions and gastric adenomas [2]. Since that time, very few additional cases of GCP have been reported, and in these instances GCP was initially thought to represent Ménétrier's disease, [3-5] gastric adenocarcinoma, [6,7] inverted hyperplastic polyps, [8] and other pathologies. This report describes a rare case of a GCP in the antrum of a surgery-naïve 39 year-old female which endoscopically and sonographically was consistent with a gastrointestinal stromal tumor (GIST). A comprehensive review and discussion of the histogenesis, diagnosis, and management of GCP is also provided.

\section{Case Report}

A 39 year-old asymptomatic female, with no history of gastric surgery underwent an abdominal sonogram for surveillance of a known focal nodular hyperplasia of the liver. She had no other significant past medical or surgical history, and took no medications. Sonography revealed a $3 \mathrm{~cm}$ submucosal mass in the gastric antrum. Physical examination revealed a non-tender, non-distended abdomen without hepatosplenomegaly or other abdominal masses. Laboratory studies revealed normal hemoglobin and liver function tests (LFTs). A contrastenhanced abdominal computed tomography (CT) scan revealed a $3 \times 2 \mathrm{~cm}$ hypodense mass in the gastric an- 
trum without evidence of outlet obstruction (Figures 1(a1) and (a2)). The patient underwent an esophagogastroduodenoscopy (EGD), endoscopic ultrasound (EUS), and mucosal/fine needle aspiration (FNA) biopsy of a $3 \mathrm{~cm}$ subepithelial gastric mass located just proximal to the pylorus with normal overlying mucosa (Figure 1(b)). Superficial mucosal biopsies revealed benign superficial gastric mucosa with focal chronic inflammation. The welldefined, hypo-echoic antral mass was confined to the submucosa on EUS. There were no perigastric or celiac lymph nodes identified (Figure 1(c)). Three 25 gauge and two 22 gauge FNA biopsies of the mass were nondiagnostic, but given the clinical and radiographic findings, a diagnosis of GIST was suspected.

The patient underwent a laparoscopic-assisted antrectomy with Roux-en-Y reconstruction. Gross review revealed a tan-pink, polypoid and rubbery submucosal lesion measuring $3.5 \times 3.0 \times 1.5 \mathrm{~cm}$ with pathologically clear $4.5 \mathrm{~cm}$ proximal and $3.7 \mathrm{~cm}$ distal margins (Figure 2(a)). Intraoperative frozen sections revealed an edematous spindle cell neoplasm with a focus of glandular inclusions suspicious of GIST (Figures 2(b1) and (b2)). Final microscopic evaluation revealed a submucosal cystic structure lined by benign appearing antral-to-pyloric type gastric mucosa with surrounding hypertrophic muscle tissue consistent with gastritis cystica profunda (Figures 2(c1) and (c2)). Immunostaining for CD34, c-Kit (CD 117), and S100 were negative, effectively excluding the diagnosis of GIST.

\section{Results}

Thirty-seven cases of GCP have been documented, including the current case reported here. Clinical and treatment data are detailed in Table 1. Among these 37 patients were 29 men and 8 women (M:F ratio, 3.6:1) with

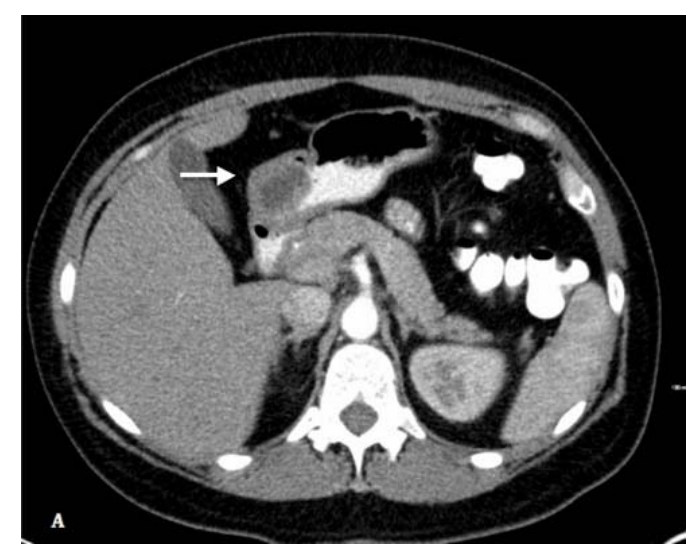

(a1)

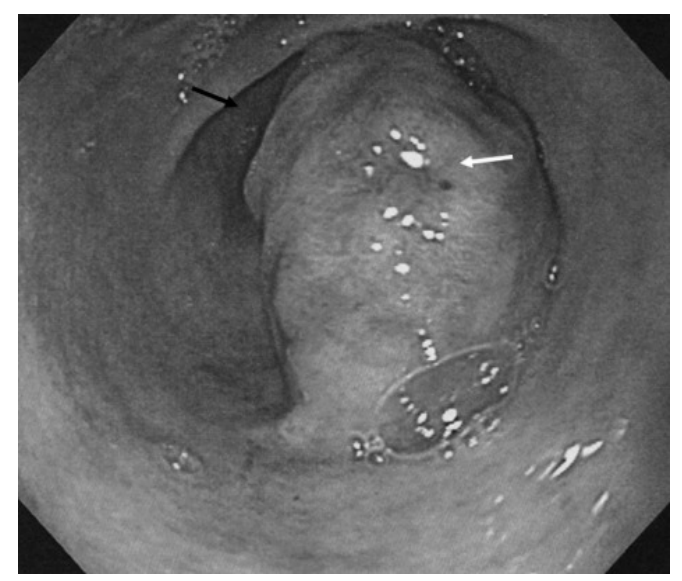

(b)

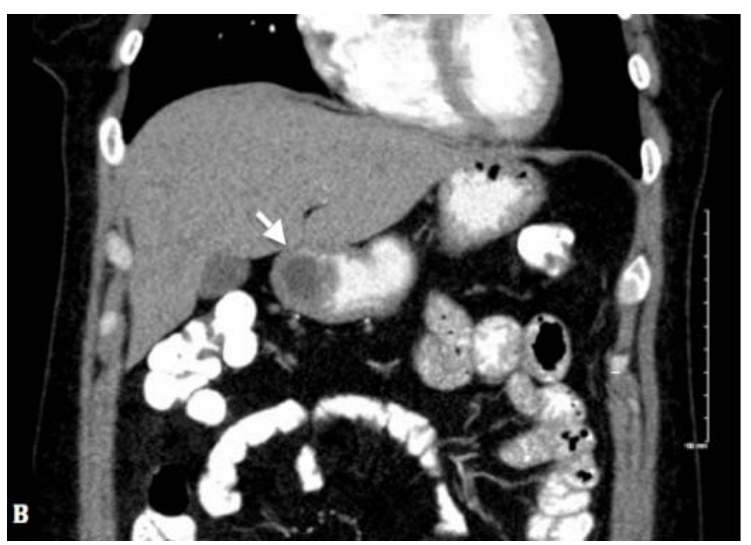

(a2)

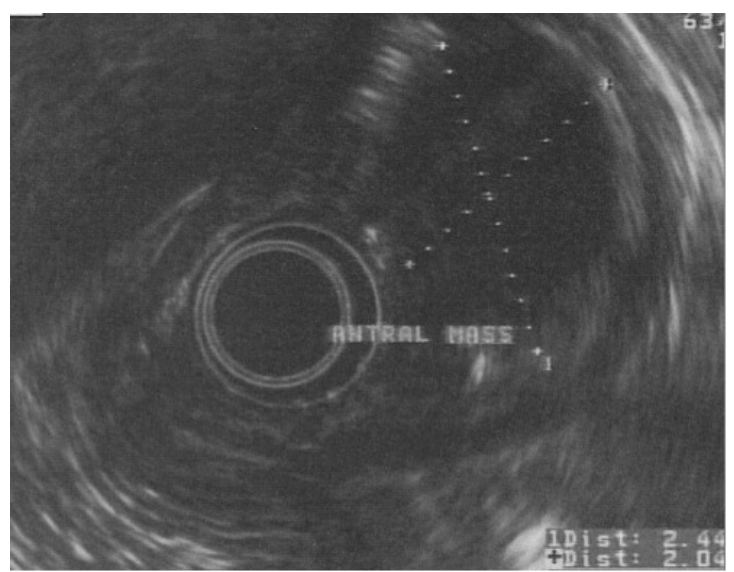

(c)

Figure 1. (a): Axial (1) and coronal (2) contrast-enhanced computed tomography (CT) images revealing a $3.2 \times 2.3 \mathrm{~cm}$ nonenhancing, partially necrotic mass (white arrows) in the gastric antrum located just proximal to the pylorus; (b): Esophagogastroduodenoscopy (EGD) image demonstrates a $3 \mathrm{~cm}$ subepithelial gastric mass with a lobulated contour located immediately proximal to the pylorus (black arrow) covered by glistening pink mucosa with an erythematous focus (white arrow); (c): Radial endoscopic ultrasound image revealing intact gastric wall layers. The well-demarcated antral lesion (dotted $\mathrm{X}$ ) represents a $2.4 \times 2.0 \mathrm{~cm}$ homogeneous, hypocheoic mass that arises completely from within the submucosal layer. 


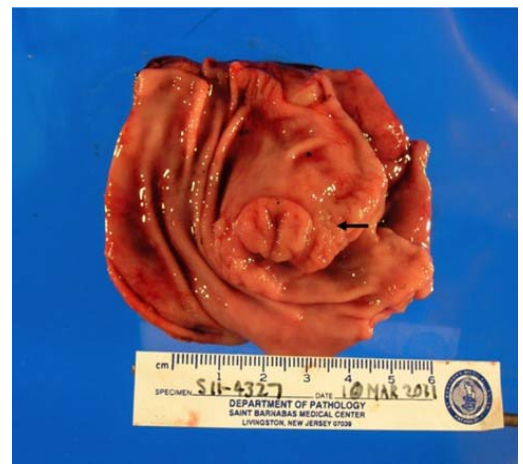

(a)

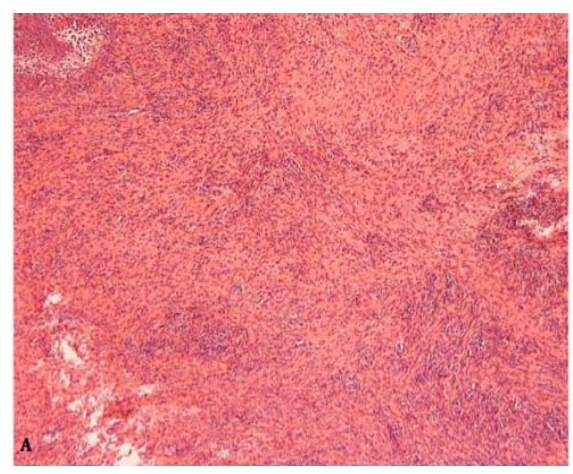

(b1)

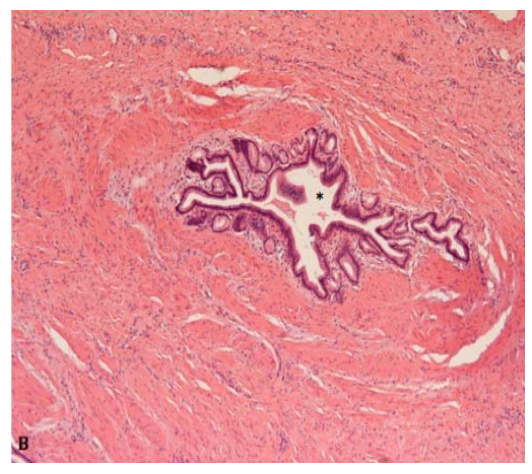

(b2)

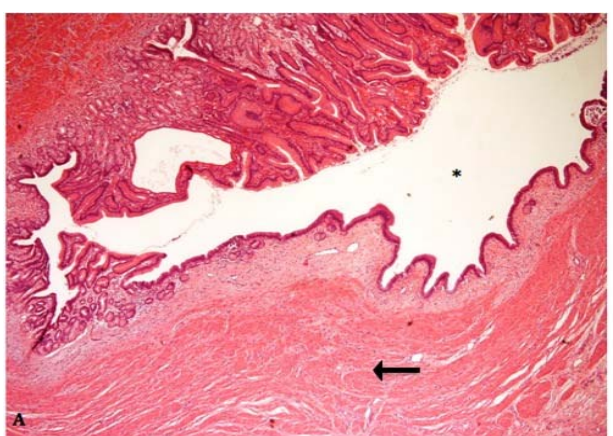

(c1)

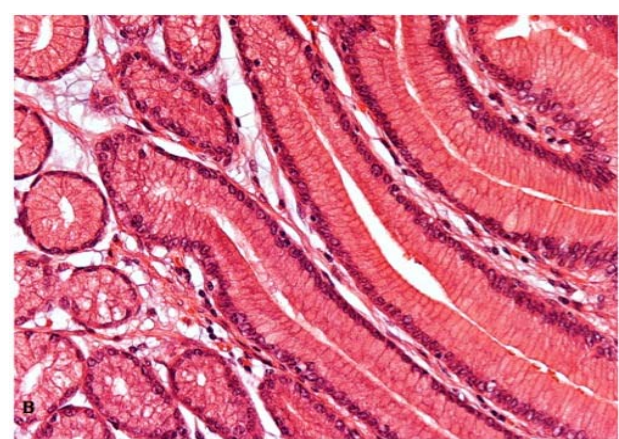

(c2)

Figure 2. (a): Gross pathologic specimen demonstrates a rubbery, antral lesion confined to the lesser curvature with central ulceration consistent with previous biopsy (black arrow). The remaining mucosa is tan and glistening with focal areas of hemorrhage; (b): Histologic examination of the submitted specimen revealed a submucosal spindle cell proliferation (1) with an isolated glandular inclusion (*) (2) (Hematoxylin-Eosin, 40×); (c): (1) Low power magnification view of the specimen demonstrates dilated, heterotopic gastric glands $(*)$ in the submucosa with surrounding muscular hypertrophy (black arrow). (Hematoxylin-Eosin, 20×) (2) On higher magnification, the irregular cystic dilations are lined by antral-to-pyloric type epithelium in a background of mucoid submucosal stroma (Hematoxylin-Eosin, 40×).

an overall mean age of 60.5 years (range, 39 - 81 years). The mean age among women was 55.6 years (range, 39 79 years), and the mean age among men was 62.2 years (range, 39 - 81 years). The most common anatomic GCP location was the gastric body (62\%) followed by the fundus (24\%), antrum (8\%), and cardia (6\%); some lesions were at the junction of body and antrum. Abdominal pain was the most common presenting complaint (27\%) followed by bleeding/anemia (16\%), fullness (8\%), and anorexia/weight loss (8\%). GCP was an incidental finding in $19 \%$ of patients. Prior gastric resection was described in $65 \%$ of patients. Of the thirty-seven cases described, treatment plans were provided for only twenty two (59\%). Treatments included complete excision (73\%), endomucosal resection (18\%), polypectomy (4.5\%), and surveillance (4.5\%). When complete excision was performed, there have been no recurrences reported.

\section{Discussion}

GCP is a rare gastric lesion characterized by the presence of gastric glands in the submucosa of the stomach with normal overlying mucosa and is often mistaken for other more common gastric pathologies [3-8]. An unspecified mucosal insult or injury is widely accepted as the nidus for GCP genesis, however, the pathophysiology is largely unknown. Whether GCP develops secondary to chronic inflammation, foreign body reaction or ischemic injury is unclear, but some interruption of the muscularis mucosa allows migration of epithelial cells into the submucosal layer and subsequent cystic dilation [6]. The majority of reported cases occurred in patients with a history of gastric surgery (65\%), however, as in the current case, GCP has been described in non-operated patients as well [3, $6,9,10]$. Mucosal prolapse and duodenal reflux which may occur following gastric surgery are believed to propagate the cystic changes observed within the submucosa [1,11-14]. In animal studies performed on Wistar rats, GCP was observed following both Billroth I and Billroth II partial gastrectomies, although a significantly higher incidence was noted following a Billroth II procedure [11].

Since the initial description of a GCP by Littler and Gleibermann, significant debate has ensued over the malignant potential of these lesions. Historically, the pres- 
Table 1. All published cases of Gastritis cystica profunda from 1972-2011.

\begin{tabular}{|c|c|c|c|c|c|c|}
\hline Study & Location & Age (years) & Sex & $\begin{array}{l}\text { Prior Gastric } \\
\text { Surgery }\end{array}$ & Presenting Symptoms & Treatment \\
\hline Littler et al., 1972 [1] & Fundus & 47 & M & $\mathrm{Y}$ & $\begin{array}{l}\text { Epigastric pain, } \\
\text { melena, anemia }\end{array}$ & $\begin{array}{l}\text { Partial gastrectomy with } \\
\text { gastroenteric anastomosis }\end{array}$ \\
\hline Béchade et al., 2007 [3] & Fundus & 79 & $\mathrm{~F}$ & $\mathrm{~N}$ & Epigastric pain & Endomucosal resection (EMR) \\
\hline Lim et al., 2010 [4] & Antrum & 63 & $\mathrm{~F}$ & $\mathrm{~N}$ & Incidental & Partial gastrectomy \\
\hline Okada et al., 1994 [5] & Body/Antrum & 51 & $\mathrm{~F}$ & $\mathrm{~N}$ & Abdominal pain & Endomucosal resection (EMR) \\
\hline Okada et al., 1994 [5] & Body/Antrum & 63 & M & $\mathrm{N}$ & Melena & Endomucosal resection (EMR) \\
\hline Moon et al., 2010 [6] & Body & 77 & M & $\mathrm{Y}$ & Incidental & Total Gastrectomy \\
\hline Moon et al., 2010 [6] & Antrum & 76 & M & $\mathrm{N}$ & Anorexia & Endomucosal resection (EMR) \\
\hline Tsuji et al., 2008 [7] & Body/Antrum & 61 & M & $\mathrm{N}$ & Epigastric pain & $\begin{array}{l}\text { Partial gastrectomy with regional } \\
\text { lymph node dissection }\end{array}$ \\
\hline Yamashita et al., 2002 [8] & Body & 69 & M & $\mathrm{N}$ & Melena & Partial gastrectomy \\
\hline Yamashita et al., 2002 [8] & Body & 81 & M & $\mathrm{N}$ & Vomiting, fullness & Partial gastrectomy \\
\hline Koga et al. 1979, [12] & Fundus & 39 & M & $\mathrm{Y}$ & Epigastric pain, fullness & Partial gastrectomy \\
\hline Koga et al. 1979, [12] & Fundus & 49 & M & $\mathrm{Y}$ & Epigastric pain & Partial gastrectomy \\
\hline Koga et al. 1979, [12] & Fundus & 62 & M & $\mathrm{Y}$ & Incidental & Partial gastrectomy \\
\hline Koga et al. 1979, [12] & Fundus & 63 & M & $\mathrm{Y}$ & Incidental & Partial gastrectomy \\
\hline Qizilbash, 1975 [14] & Body & 67 & M & $\mathrm{Y}$ & Incidental & N/A (post-mortem) \\
\hline Fonde et al., 1986 [9] & Body/Antrum & 50 & M & $\mathrm{N}$ & $\begin{array}{l}\text { Epigastric pain, fullness, } \\
\text { weight loss, hematemesis }\end{array}$ & $\begin{array}{l}\text { Total gastrectomy with Roux-en-Y } \\
\text { esophagojejunostomy }\end{array}$ \\
\hline Park et al., 2001 [10] & Fundus & 44 & $\mathrm{~F}$ & $\mathrm{~N}$ & Epigastric pain & Polypectomy \\
\hline Mitomi et al., 1998 [15] & Body & 44 & M & $\mathrm{N}$ & Abdominal pain & Total gastrectomy \\
\hline Tomizuka et al., 2008 [19] & Cardia & 78 & M & $\mathrm{Y}$ & Incidental & $\begin{array}{l}\text { Partial gastrectomy with Roux-en-Y } \\
\text { esophagojejunostomy }\end{array}$ \\
\hline Itte et al., 2008 [23] & Fundus & 50 & M & $\mathrm{Y}$ & $\begin{array}{l}\text { Epigastric pain, } \\
\text { hematemesis, anemia }\end{array}$ & Surveillance \\
\hline Kurland et al., 2006 [24] & Cardia & 75 & M & $\mathrm{Y}$ & Anemia, GI bleed & $\begin{array}{l}\text { Partial gastrectomy with Roux-en-Y } \\
\text { esophagojejunostomy }\end{array}$ \\
\hline Wu et al., 1994 [25] & Fundus & 58 & $\mathrm{~F}$ & $\mathrm{~N}$ & Anorexia, weight loss & $\begin{array}{l}\text { Total gastrectomy with Roux-en-Y } \\
\text { esophagojejunostomy }\end{array}$ \\
\hline Franzin et al., 1981 [2] & Body & $42-71$ & $12 \mathrm{M}: 2 \mathrm{~F}$ & $\mathrm{Y}$ & NR & NR \\
\hline Current study, 2011 & Antrum & 39 & $\mathrm{~F}$ & $\mathrm{~N}$ & Incidental & $\begin{array}{l}\text { Partial gastrectomy with Roux-en-Y } \\
\text { esophagojejunostomy }\end{array}$ \\
\hline
\end{tabular}

*Franzin et al., 1981 describes 14 cases of GCP based on histological findings alone. The authors do not describe the clinical characteristics or treatment of the patients. The patients were 42 - 71years old: 12 male and 2 female. All lesions were located in body of the stomach. N/A: Not applicable, NR: Not recorded.

ence of submucosal glands in GCP was not thought to represent cancer. Instead they were likened to the histological changes seen in patients with longstanding peptic ulcer disease (PUD) and gastritis [9,12]. More recent reports have described dysplastic changes within the submucosal glands of select GCP cases suggesting an adenocarcinomatous precursor lesion [6,7]. Mitomi et al. described increased expression of Ki-67, p53, and p21 in GCP lesions indicative of increased epithelial proliferation and increased DNA repair that could be linked to malignant progression [15]. Furthermore, targeted deletion of a subunit in apical $\mathrm{K}+$ channels in parietal cells in mice (KCNE2) has been noted to result in an increased rate of GCP formation and overt neoplasia suggesting that KCNE2 disruption is a possible risk factor for gastric neoplasia [16].

The differential diagnosis of submucosal lesions within the stomach includes lipoma, leiomyoma, leiomyosarcoma, lymphoma, GIST, and GCP. Although gastric adenocarcinoma begins as a mucosal lesion, gastric cancer can also 
present with normal mucosa in $20 \%$ - 30\% of cases, further obscuring and adding to the difficulty of GCP diagnosis [17]. It has proven nearly impossible to preoperatively distinguish GCP from other gastric lesions based on symptoms alone. A comparison between the demographics, presenting symptoms, and histological appearance of GCP, gastric adenocarcinoma, and GIST is provided in Table 2. Clinical manifestations of GCP are typically nonspecific, leading to significant diagnostic uncertainty. Histological examination of biopsy specimen is typically non-diagnostic and a formal surgical excision is usually required. Compared to gastric adenocarcinoma, GCP occurs in younger, male patients and rarely presents with weight loss, anorexia, or abdominal fullness. In regards to distinguishing GCP from GIST, GCP occurs in a similar age range, but is almost four times more common in men, and only rarely associated with anemia or gastrointestinal bleeding (16\%) compared to GIST (72\%).

Though GCP cannot be diagnosed on endoscopic evaluation alone, GCP generally lacks mucosal erosion, ulceration, marked fibrosis, or firm consistency, which can occur with gastric adenocarcinoma and less commonly with GIST. On EUS, GCP typically appears as a homogeneous, hypoechoic cystic mass with minimal, if any, solid component [10]. Radiographically, GIST and GCP both appear as hypoechoic, intramural polypoid masses with cystic changes [18]. Because the mucosa is spared in GCP, submucosal FNA biopsies are required for a definitive diagnosis, [19] although these too are often nondiagnostic as in the current case described [12]. Histologic examination of a surgically excised specimen is also difficult and may not be possible until the definite surgical excision specimen can be fully evaluated. Immunohistochemical staining of biopsy or surgical specimen is important to make the diagnosis of GCP and exclude other lesions such as GIST, neuroma, and leiomyoma. CD34 is positive in $\sim 60 \%-70 \%$ of GISTs, while S100 antigen stains positive in only 5\% [20]. c-Kit (CD117) expression is the most sensitive marker of GIST and is positive in $~ 90 \%-95 \%$ cases [21]. The accuracy of EUS-FNA with immunostaining in preoperative GIST diagnosis has been reported at $91 \%$ - 100\% [22].

A defined treatment strategy for GCP has not been well described given the rarity of the lesions and the difficulty in diagnosing them preoperatively. To date, all but one case of GCP in which treatment has been detailed were managed with definite surgical resection. In this one case, the patient was operated upon for severe upper gastrointestinal bleeding and ulcer biopsy demonstrated GCP on final histopathology [23]. Given the lack of a pathognomonic endoscopic or radiographic appearance of GCP, surveillance cannot be endorsed. No cases of local recurrence or distant metastasis for GCP follow-

Table 2. A comparison between the common clinical presentations of Gastritis cystica profunda, Gastric cancer, and gastrointestinal Stromal tumor.

\begin{tabular}{|c|c|c|c|}
\hline & Gastritis Cystica Profunda & Gastric Cancer & Gastrointestinal Stromal Tumor \\
\hline Incidence & 37 reported cases & $7.1 / 100,000[29]$ & $0.32 / 100,000[28]$ \\
\hline Mean age at diagnosis (range) & $60.5(39-81)$ & $69.7(<19-70+)[35]$ & $60(40-80)[31]$ \\
\hline Anatomic location & Submucosal & Mucosal & Submucosal \\
\hline Gross appearance & $\begin{array}{l}\text { Soft intramural mass } \\
\text { with smooth mucosa }\end{array}$ & $\begin{array}{l}\text { Varied: protruding, non-protruding, } \\
\text { or excavated lesion +/- ulcerated } \\
\text { mucosa and definite limits [37] }\end{array}$ & $\begin{array}{l}\text { Well-circumscribed, intramural } \\
\text { mass with smooth mucosa [26] }\end{array}$ \\
\hline Histologic appearance & $\begin{array}{l}\text { Cystic gastric glandular } \\
\text { inclusions in submucosa }\end{array}$ & $\begin{array}{l}\text { Single or small clusters of cells with } \\
\text { marked cytological atypia } \\
\text { (pleomorphic nuclei with prominent } \\
\text { nucleoli) and architectural atypia } \\
\text { (necrosis, cribriforming)[34] }\end{array}$ & $\begin{array}{l}\text { Spindle cells with eosinophilic } \\
\text { cytoplasm arranged in whirls [26] }\end{array}$ \\
\hline \multicolumn{4}{|l|}{ Symptom } \\
\hline Incidental (\%) & $19 \%$ & $20 \%[38]$ & $30 \%[32]$ \\
\hline Weight loss (\%) & $8 \%$ & $62 \%[35]$ & $32 \%[33]$ \\
\hline GI bleeding or anemia (\%) & $16 \%$ & $20 \%[35]$ & $72 \%[36]$ \\
\hline Pain or fullness (\%) & $27 \%$ & $70 \%[35]$ & $32 \%[36]$ \\
\hline 5-year survival rate & $100 \%$ & $27.1 \%[29]$ & $35 \%[30]$ \\
\hline Curative resection & $100 \%$ & $41.2 \%[31]$ & $54 \%[30]$ \\
\hline
\end{tabular}


ing surgical resection have been reported.

In summary, GCP is a rare gastric submucosal tumor that is confused with other more common gastric pathologies. It is important to consider GCP in the differential diagnosis of patients presenting with suspicious submucosal gastric lesions, irrespective of nondiagnostic EUS-FNA biopsies. Future studies may help to elucidate the natural history of this disease process, as well as the possibility for malignant potential, thus permitting more evidence-based treatment strategies. Until then, known GCP or suggestive submucosal gastric lesions should be excised using established surgical oncology principles.

\section{REFERENCES}

[1] E. R. Littler and E. Gleibermann, "Gastritis Cystica Polyposa. Gastric Mucosal Prolapse at Gastroenterostomy Site, with Cystic and Infiltrative Epithelial Hyperplasia," Cancer, Vol. 29 No. 1, 1972, pp. 205-209. doi.org/10.1002/1097-0142(197201)29:1<205::AID-CNC R2820290130>3.0.CO;2-J

[2] G. Franzin and P. Novelli, "Gastritis Cystica Profunda," Histopathology, Vol. 5, No. 5, 1981, pp. 535-547. doi.org/10.1111/j.1365-2559.1981.tb01817.x

[3] D. Béchade, J. Desramé and J. P. Algayres, "Gastritis Cystica Profunda in a Patient with No History of Gastric Surgery,” Endoscopy, Vol. 39, 2007, pp. 80-81. doi.org/10.1055/s-2006-945070

[4] J. K. Lim, Y. J. Jang, M. K. Jung, H. K. Ryeom, G. C. Kim and J. Bae, "Ménétrier Disease Manifested by Polyposis in the Gastric Antrum and Coexisting with Gastritis Cystica Profunda," Gastrointestinal Endoscopy, Vol. 72, No. 5, 2010, pp. 1098-1100. doi.org/10.1016/j.gie.2010.02.020

[5] M. Okada, Y. Iizuka, K. Oh, H. Murayama and T Maekawa, "Gastritis Cystica Profunda Presenting as Giant Gastric Mucosal Folds: The Role of Endoscopic Ultrasonography and Mucosectomy in the Diagnostic Work-Up,” Gastrointestinal Endoscopy, Vol. 40, No. 5, 1994, pp. 640644. doi.org/10.1016/S0016-5107(94)70272-1

[6] S. K. Moon, K. O. Kim, S. H. Park, K. S. Yoo, C. H. Park, J. H. Kim, C. K. Park and S. Y. Jun, "Gastritis Cystica Profunda Accompanied by Multiple Early Gastric Cancers," Korean Journal of Gastroenterology, Vol. 55, No. 5, 2010, pp. 325-330. doi.org/10.4166/kjg.2010.55.5.325

[7] T. Tsuji, M. Iwahashi, M. Nakamori, K. Ueda, K. Ishida, T. Naka, T. Ojima, H. Akamatsu and H. Yamaue, "Multiple Early Gastric Cancer with Gastritis Cystica profunda Showing Various Histological Types,” Hepatogastroenterology, Vol. 55, No. 84, 2008, pp. 1150-1152.

[8] M. Yamashita, M. Hirokawa, M. Nakasono, H. Kiyoku, N. Sano, M. Fujii, T. Koyama, S. Yoshida and T. Sano, "Gastric Inverted Hyperplastic Polyp. Report of Four Cases and Relation to Gastritis Cystica Profunda," APMIS, Vol. 110, No. 10, 2002, pp. 717-723. doi.org/10.1034/j.1600-0463.2002.1101005.x

[9] E. C. Fonde and C. B. Rodning, "Gastritis Cystica Pro- funda," American Journal of Gastroenterology, Vol. 81, No. 6, 1986, pp. 459-464.

[10] J. S. Park, S. J. Myung, H. Y. Jung, S. K. Yang, W. S. Hong, J. H. Kim, G. H. Kang, H. K. Ha and Y. I. Min, "Endoscopic Treatment of Gastritis Cystica polyposa Found in an Unoperated Stomach," Gastrointestinal Endoscopy, Vol. 54, No. 1, 2001, pp. 101-103. doi.org/10.1067/mge.2001.114412

[11] T. Kamata, "Experimental Studies on the Development of residual Stomach Cancer-Comparison of Billroth I and Billroth II,” Nippon Geka Gakkai Zasshi, Vol. 94, No. 2, 1993, pp. 104-113.

[12] S. Koga, H. Watanabe and M. Enjoji, "Stomal Polypoid Hypertrophic Gastritis: A Polypoid Gastric Lesion at Gastroenterostomy Site,” Cancer, Vol. 43, No. 2, 1979, pp. 647-657.

doi.org/10.1002/1097-0142(197902)43:2<647::AID-CNC R2820430236>3.0.CO;2-Y

[13] K. Mukaisho, K. Miwa, H. Kumagai, M. Bamba, H. Sugihara and T. Hattori, "Gastric Carcinogenesis by Duodenal Reflux through Gut Regenerative Cell Lineage," Digestive Diseases and Sciences, Vol. 48, No. 11, 2003, pp. 2153-2158. doi.org/10.1023/B:DDAS.0000004519.26201.a4

[14] A. H. Qizilbash, "Gastritis Cystica and Carcinoma Arising in Old Gastrojejunostomy Stoma,” Canadian Medical Association Journal, Vol. 112, No. 12, 1975, pp. 14321433.

[15] H. Mitomi, K. Iwabuchi, A. Amemiya, G. Kaneda, K. Adachi and T. Asao T, "Immunohistochemical Analysis of a Case of Gastritis Cystica Profunda Associated with Carcinoma Development," Scandinavian Journal of Gastroenterology, Vol. 33, No. 11, 1998, pp. 1226-1229. doi.org/10.1080/00365529850172610

[16] T. K. Roepke, K. Purtell, E. C. King, K. M. La Perle, D. J. Lerner and G. W. Abbott, "Targeted Deletion of Kcne2 Causes Gastritis Cystica Profunda and Gastric Neoplasia,” PLoS One, Vol. 5, No. 7, 2010, p. e11451. doi.org/10.1371/journal.pone.0011451

[17] M. Vauhkonen, H. Vauhkonen and P. Sipponen, "Pathology and Molecular Biology of Gastric Cancer,” Best Practice and Research Clinical Gastroenterology, Vol. 20, No. 4, 2006, pp. 651-674. doi.org/10.1016/j.bpg.2006.03.016

[18] R. Kochhar, P. Manoharan, M. Leahy and M. B. Taylor, "Imaging in Gastrointestinal Stromal Tumours: Current Status and Future Directions,” Clinical Radiology, Vol. 65, No. 8, 2010, pp. 584-592. doi.org/10.1016/j.crad.2010.02.006

[19] T. Tomizuka, T. Mazaki, K. Mado, A. Henmi, Y. Ishii, H. Masuda and T. Takayama, "A Case of Gastritis Cystica Profunda,” Surgery, Vol. 143 No. 3, 2008, pp. 449-450. doi.org/10.1016/j.surg.2007.02.009

[20] J. A. Laurini and J. E. Carter, "Gastrointestinal Stromal Tumors: A Review of the Literature," Archives of $\mathrm{Pa}$ thology and Laboratory Medicine, Vol. 134, No. 1, 2010, pp. 134-141.

[21] C. D. Fletcher, J. J. Berman, C. Corless, F. Gorstein, J. 
Lasota, B. J. Longley, M. Miettinen, T. J. O'Leary, H. Remotti, B. P. Rubin, B. Shmookler, L. H. Sobin and S. W. Weiss, "Diagnosis of Gastrointestinal Stromal Tumors: A Consensus Approach,” International Journal of Surgical Pathology, Vol. 10, No. 2, 2002, pp. 81-89. doi.org/10.1177/106689690201000201

[22] K. Akahoshi and M. Oya, "Gastrointestinal Stromal Tumor of the Stomach: How to Manage?" World Journal of Gastrointestinal Endoscopy, Vol. 2, No. 8, 2010, pp. 271277. doi.org/10.4253/wjge.v2.i8.271

[23] V. Itte, I. H. Mallick and P. J. Moore, "Massive Gastrointestinal Haemorrhage Due to Gastritis Cystica Profunda,” Cases Journal, Vol. 1, No. 1, 2008, p. 85.

[24] J. Kurland, S. DuBois, C. Behling and T. Savides, "Severe Upper-GI Bleed Caused by Gastritis Cystica Profunda," Gastrointestinal Endoscopy, Vol. 63, No. 4, 2006, pp. 716-717. doi.org/10.1016/j.gie.2005.11.027

[25] M. T. Wu, H. B. Pan, P. H. Lai, J. M. Chang, S. H. Tsai and C. W. Wu, "CT of Gastritis Cystica Polyposa," Abdominal Imaging, Vol. 19, No. 1, 1994, pp. 8-10. doi.org/10.1007/BF02165852

[26] A. Machairas, E. Karamitopoulou, D. Tsapralis, T. Karatzas, N. Machairas and E. P. Misiakos, "Gastrointestinal Stromal Tumors (GISTs): An Updated Experience,” Digestive Diseases and Sciences, Vol. 55, No. 12, 2010, pp. 3315-3327. doi.org/10.1007/s10620-010-1360-9

[27] M. Miettinen and J. Lasota, "Gastrointestinal Stromal Tumors: Review on Morphology, Molecular Pathology, Prognosis, and Differential Diagnosis," Archives of Pathology and Laboratory Medicine, Vol. 10, 2006, pp. 14661478.

[28] J. L. Rubin, M. Sanon, D. C. Taylor, J. Coombs, V. Bollu and L. Sirulnik, "Epidemiology, Survival, and Costs of Localized Gastrointestinal Stromal Tumors,” International Journal of General Medicine, Vol. 4, 2011, pp. 121-130.

[29] National Cancer Institute, DCCPS, Surveillance Research Program, Cancer Statistics Branch, "Surveillance, Epidemiology, and End Results (SEER) Program Research Data (1973-2008),” 2011. http://www.seer.cancer.gov/

[30] R. P. DeMatteo, J. J. Lewis, D. Leung, S. S. Mudan, J. M. Woodruff and M. F. Brennan, "Two Hundred Gastroin- testinal Stromal Tumors: Recurrence Patterns and Prognostic Factors for Survival,” Annals of Surgery, Vol. 231, No. 1, 2000, pp. 51-58. doi.org/10.1097/00000658-200001000-00008

[31] G. F. Cenitagoya, C. K. Bergh and J. Klinger-Roitman, “A Prospective Study of Gastric Cancer. 'Real' 5-Year Survival Rates and Mortality Rates in a Country with High Incidence,” Digestive Surgery, Vol. 15, No. 4, 1998, pp. 317-322. doi.org/10.1159/000018645

[32] P. S. Sepe and W. R. Brugge, "A Guide for the Diagnosis and Management of Gastrointestinal Stromal Cell Tumors," Nature Reviews Gastroenterology and Hepatology, Vol. 6, No. 6, 2009, pp. 363-371.

doi.org/10.1038/nrgastro.2009.43

[33] B. M. Yan, G. G. Kaplan, S. Urbanski, C. L. Nash and P. L. Beck, "Epidemiology of Gastrointestinal Stromal Tumors in a Defined Canadian Health Region: A Population-Based Study,” International Journal of Surgical Pathology, Vol. 16, No. 3, 2008, pp. 241-250. doi.org/10.1177/1066896907306967

[34] A. Srivastava and G. Y. Lauwers, "Gastric Epithelial Dysplasia: The Western Perspective,” Digestive and Liver Disease, Vol. 40, 2008, pp. 641-649. doi.org/10.1016/j.dld.2008.02.039

[35] H. J. Wanebo, B. J. Kennedy, J. Chmiel, G. Steele Jr., D. Winchester and R. Osteen, "Cancer of the Stomach. A Patient Care Study by the American College of Surgeons," Annals of Surgery, Vol. 218, No. 5, 1993, pp. 583-592. doi.org/10.1097/00000658-199321850-00002

[36] F. F. Chou, H. L. Eng and S. M. Sheen-Chen, "Smooth Muscle Tumors of the Gastrointestinal Tract: Analysis of Prognostic Factors,” Surgery, Vol. 119, No. 2, 1996, pp. 171-177. doi.org/10.1016/S0039-6060(96)80165-6

[37] T. L. Ang, C. J. Khor and T. Gotoda, "Diagnosis and Endoscopic Resection of Early Gastric Cancer,” Singapore Medical Journal, Vol. 51, No. 2, 2010, pp. 93-100.

[38] A. Matsukuma, M. Furusawa, H. Tomoda and Y. Seo, “A Clinicopathological Study of Asymptomatic Gastric Cancer,” British Journal of Cancer, Vol. 74, No. 10, 1996, pp. 1647-1650. doi.org/10.1038/bjc.1996.603 